\title{
Hacia una ética disruptiva
}

\section{Bolívar Echeverría}

\author{
Luis Villoro, El poder y el valor, fundamentos \\ de una ética política. México, FCE, 1997.
}

V

ivimos - cada vez resulta más claro- una época de "cinismo espontáneo". La acción buena en medio de un mundo injusto ya no puede reafirmarse, a pesar de todo, en última instancia, como tal; ni suponiendo, como lo hacían los premodernos, que la justicia es asunto seguramente divino, que desborda el alcance de nuestra situación individual, ni suponiendo tampoco, como lo hacen todavía los modernos, que la justicia será un privilegio de la vida futura, que justifica o "salva" nuestra acción por adelantado en la medida en que ella contribuya al progreso. El reino de la igualdad de derechos y oportunidades para todos, el estado de justicia, ha sido expulsado del futuro posible; lo ha hecho la convicción científica de que el planeta, ni con la ayuda de la más productiva de las técnicas, está en capacidad física de soportar una generalización de las exigencias de vida civilizada propias del tipo de ser humano que ha moldeado la modernidad. El planeta sólo parece admitir como sustentable la existencia de un mundo para pocos; la injusticia, es decir, la marginación o incluso el exterminio de "los otros" parece ser una "condición técnica" de la reproducción del mundo moderno.

Reafirmarnos individualmente, en nuestra práctica cotidiana, como seres humanos modernos parece ahora requerir de nosotros, no sólo, como hasta hace medio siglo, que contemos con una injusticia en sí misma indeseable y por lo pronto irremediable, sino que deseemos esa injusticia, que seamos partícipes de una "voluntad de injusticia" que estaría inscrita en el propio mundo de la vida.

Re-primitivizada, al cerrarse en torno al monopolio de la innovación tecnológica y de los recursos no renovables, la economía globalizada de un planeta de fuerzas productivas hiperdesarrolladas, tiene un efecto paradójico sobre la vida que los seres humanos pueden llevar gracias a ella: la "realdeaniza", hace que nuevamente las razas, las religiones, las naciones, las regiones deban temer por sus "identidades" y se enfrenten entre sí para 
salvaguardarlas. La gigantesca "tribu" de nosotros, los modernos, debe afirmarse así frente a los otros, los prescindibles: los premodernos, los posmodernos y los modernos a medias. La injusticia de la que ellos son víctimas en su relación con nosotros es una injusticia que nosotros, si queremos vivir como vivimos, debemos, cínicamente, desear y defender.

En un panorama como éste no cabe duda que la necesidad de un replanteamiento de la cuestión acerca de qué es y qué puede ser la ética en el terreno de la vida política es una necesidad que resulta, si no urgente -puesto que nada que sea teórico puede serlo-, sí evidente.

Por esta razón agradezco a los organizadores de esta mesa el raro privilegio de poder comentar, a manera de presentación, un libro excepcional como es éste de Luis Villoro, que lleva el título de El poder y el valor.

Excepcional, porque pertenece a un tipo de libros cuya redacción muy pocos autores contemporáneos tienen la capacidad y el valor de emprender; un libro que es, a su manera, todo un tratado sistemático acerca de los "fundamentos de una ética política".

Pero excepcional también, porque, muy al contrario de quienes, cuando hablan de política, se llenan la boca con la palabra "ética", con el fin de eludir el problema del poder y de su ubicación y repartición en la sociedad -problema del que no puede prescindirse al hablar de política-, y que al hacerlo escamotean de paso la reproblematización radical que exige actualmente el problema de la ética, Luis Villoro trata en verdad de la relación que existe entre política y ética, y lo hace de manera directa y a fondo, sin recurrir a "licencias" ni literarias ni teóricas; sin rodeos ni parcelaciones del tema, sin dar nada por supuesto ni dejar nada esencial para más tarde.

En el libro de Luis Villoro impresiona la insistencia con la que acosa a su objeto, la ética política; su manera de examinarlo desde diversas perspectivas y bajo luces muy distintas, girando en torno a él una y otra vez hasta componer una representación conceptual completa y coherente del mismo: una teoría de los valores éticos, una teoría de la política y una teoría de la relación entre ética y política. Pero lo que más llama la atención en él, y vuelve intensa -apasionada incluso- su lectura, es que se trata de un libro clara e insistentemente propositivo; un libro que intenta de manera abierta y retadora convencer al lector de una propuesta original en el terreno de la ética política, la propuesta de lo que su autor llama una "ética disruptiva".

Debo decir, de entrada, que comparto plenamente la idea de Luis Villoro de que, en la historia que nos ha tocado vivir, el momento "disruptivo" es el eje de todo comportamiento moralmente válido. Éticamente válida es, para él, aquella política que promueve una "disrupción": la conversión radical de la "voluntad particular" en "voluntad general", del convenio "conforme al poder" en convenio "conforme a valor", del "bürger" en "citoyen", de la "socie- 
dad burguesa" en "sociedad política". Mi comentario no tiene una intención contrapuesta a la argumentación general del libro, dirigida a fundamentar esta definición del acuerdo entre política y ética; pretende más bien avanzar con ella y fortalecerla. No es, por lo demás, un comentario global sobre todo el libro sino uno particular sobre un solo paso argumental del mismo, el que tiene que ver con la teoría política de Marx (y que se encuentra en la tercera parte, intitulada "Pensamiento y cambio políticos").

Luis Villoro emplea en su argumentación un recurso al que podríamos llamar de invocación-construcción a un interlocutor virtual; es la discusión con éste, cuyas teorías expone e interpreta, la que le permite elaborar la formulación definitiva de sus ideas propias. En el libro aparecen tres interlocutores principales, cada uno en un momento crucial del proceso argumentativo: Maquiavelo, primero, a continuación Marx y finalmente Rousseau. A todos ellos el autor dedica páginas que valen por sí mismas por la agudeza y la penetración de las observaciones que contienen.

Mi comentario tiene que ver con el segundo de estos interlocutores virtuales, con el Marx que Luis Villoro invoca-construye para la formulación de su teoría de una ética política, y es un comentario crítico.

Apegado a la tradición más tolerante acerca de Marx dentro del ámbito de la filosofía política anglosajona, Luis Villoro describe el discurso del redactor del Manifiesto del Partido Comunista como un discurso desgarrado entre dos versiones a la vez indispensables e incompatibles de sí mismo, sumido en la imposibilidad de resolver las obvias dificultades que se le presentan cuando pretende encontrar alguna mediación entre ambas. La obra de Marx sería el "resultado de la tensión irresuelta entre dos discursos que corren paralelos", que no se interpenetran ni se integran ni sintetizan: por un lado, el discurso "científico" y, por otro, el discurso "normativo". El primero, que se expone abiertamente, es un discurso explicativo que pretende descubrir, más allá o más acá de toda valoración, la necesidad del tránsito histórico de la forma social actual -burguesa, capitalista- a otra superior, el socialismo o comunismo. El segundo, que recorre el mismo trayecto que el anterior, pero de manera implícita, es un discurso libertario, justificativo, valorativo, normativo. Mientras para el primero el hecho de la explotación capitalista, por ejemplo, no es ni justo ni injusto, para el segundo es antes que nada una forma de la injusticia.

Avanzando más allá de la moralidad "realmente existente", esta versión libertaria del discurso de Marx, se rige por una moralidad superior, que mira a la acción individual en el plano de un progreso posible hacia una "comunidad de hombres libres".

No cabe duda que el Marx invocado-construido en este libro estaría ante la dificultad insalvable de una necesaria duplicación descalificadora de sí mismo. Pero es un hecho, que parece escapársele a Luis Villoro, pese a su búsque- 
da de interlocutores afines, capaces de acompañarle en su tarea reflexiva, que, aparte de ese Marx esquizoide, la discusión dentro del marxismo contemporáneo conoce un Marx diferente, en el cual esa escisión no es un defecto que le sobrevenga desde afuera y lo tome desprevenido, sino un momento trascendido de su propia constitución. El discurso de este otro Marx -actuante en obras como las de un Korsch y un Lukács, de un Bloch y un Benjamin, de un Horkheimer y un Adorno, de un Kosík o un Lefebvre e incluso de un Brecht- es un discurso crítico, es decir, un discurso que "narra" la realidad moderna como constituida esencialmente por una contradicción y un conflicto "superables", y practica su narración como un momento de la superación de los mismos.

Una ética "disruptiva" como la planteada por Luis Villoro tendría en la descripción que $E l$ capital de Marx hace del modo de vida elemental en la civilización moderna - el modo capitalista de la producción, la circulación y el consumo de la riqueza material- una base de sustentación muy difícil de rebatir. Según el discurso crítico de Marx, la vida moderna deriva todos sus esplendores y todas sus miserias de la coincidencia de dos tendencias contradictorias en el proceso en el que construye su mundo: por un lado, la tendencia de ella en su "forma natural" a crear cada vez nuevas figuras para el "valor de uso" o la disfrutabilidad del mundo; por otro, la tendencia a incrementar de manera voraz e insaciable la magnitud de ese mundo, reducido y convertido a puro valor económico. Sería esta contradicción la que, vivida en la experiencia individual del ser humano moderno, del "esclavo que es su propio tratante", del asalariado que vive de alimentar el mecanismo que le impide vivir, plantea la situación de partida de una ética de la disrupción. De acuerdo a la descripción de El capital, una peculiar lucha incesante entre el "bien" y el "mal" se desarrollaría en la cotidianidad moderna; una lucha desigual en la que el proceso de creación de formas para el disfrute y para la convivencia solidaria intentaría afirmarse una y otra vez - como Sísifo- contra un destino, el que convierte a esa creación en una simple valorización del valor o acumulación de capital, que lo devolvería una y otra vez al punto de partida. La ética de la disrupción sería entonces la que llevaría al "esclavo moderno" a abandonar en su comportamiento la obediencia al destino y a arriesgarse en la aventura de "desactivarlo" a fuerza de intentar vencerlo.

El poder y el valor es uno de los libros más importantes salidos de las prensas mexicanas en el último decenio del siglo pasado. Valga este comentario-sugerencia a un pasaje del mismo como una invitación a la lectura del libro completo. 